\title{
Effect of Heat Treatment Parameters on the Mechanical and Microstructure Properties of Low-Alloy Steel
}

\author{
Mohamed H. Frihat \\ Mechanical Engineering Department, Al-Hsoun University College, Al-Balqa Applied University, Irbid, Jordan \\ Email: Mohamed frihat@YAHOO.COM
}

Received 21 April 2015; accepted 13 October 2015; published 16 October 2015

Copyright () 2015 by author and Scientific Research Publishing Inc.

This work is licensed under the Creative Commons Attribution International License (CC BY).

http://creativecommons.org/licenses/by/4.0/

(c) (i) Open Access

\begin{abstract}
This study examines the effect of heat treatment at three different temperatures of $800^{\circ} \mathrm{C}, 950^{\circ} \mathrm{C}$ and $1100^{\circ} \mathrm{C}$ on the microstructure and mechanical properties of low-alloy steel with an addition of manganese, chrome and lead. To determine an impact of the applied heat treatment operations, testing of mechanical properties and microstructural examinations of the steel with $0.23 \%, 0.24 \%$, $0.29 \%$ and $0.31 \% \mathrm{C}$ were conducted. This work shows that the mechanical strengths of the alloy steel are improved with increasing the heat treatment temperature. In addition, the microstructure trends toward recrystallized ferrite grains as the heat treatment temperature increases.
\end{abstract}

\section{Keywords}

Low-Alloy Steel, Heat Treatment, Microstructure, Mechanical Properties

\section{Introduction}

During the last decays, there has been a great demand for steels with higher mechanical strength, sufficient ductility and toughness. Moreover, the lightness of the steel is attractive, as in the automobile and aircraft applications. These requirements can be achieved by an increase in carbon content in a limited way, but even in the heat-treated condition the maximum strength of alloy steel can reach $700 \mathrm{MPa}$ above this value; the ductility dramatically decreases [1].

The heat treatment of alloy steels provides a high strength and yield point, combined with significant ductility even in large sections. Only thin section of plain carbon steels can be hardened via water quenching, and this is accompanied by a distortion and cracking. Alloy steels can resist corrosion and oxidation at high temperatures.

According to the Alloy Steels Research Committee (ASRC): "Carbon steels are regarded as steels containing 
not more than $0.5 \%$ manganese and $0.5 \%$ silicon, all other steels being regarded as alloy steels [2]”. The basic alloying elements added to steel are manganese, lead, nickel, chromium, molybdenum, vanadium, niobium, silicon and cobalt. The effect heat treatment of low-alloy steel was extensively studied by many researchers during the last decays. In the next paragraphs, samples of these studies are presented.

R. Roberti [3] carried out a research work to measure fracture toughness of ASME SA-542/SA-542M steel subjected to different tempering conditions to assess the effect of treatment temperatures higher than the maximum level for preweld heat treatment (PWHT) on both microstructure and toughness. It was found that, only small modifications in the microstructure are without any damage in the fracture behavior of base metal, weld metal.

Mohammad A. [4] investigated the effects of $\mathrm{Cr}$ and $\mathrm{Ni}$ on low carbon steel with undissolved carbide particles on the refining the austenite grain size. In the presence of nickel, chromium carbide is less active in austenite grain refinement than chromium carbide in absence of nickel at temperature under $975^{\circ} \mathrm{C}$. Nickel does not produce any austenite grain refinement, but the presence of nickel promotes the formation of acicular ferrites.

Petr et al. [5] considered a secondary hardening of steels containing vanadium with non-tempered welded joints and he found that it experiences a significant increase in hardness during exposure at operating temperature.

Trindade Filho et al. [6] studied four different low-alloy steel weld metals (WM) both in the welded condition and after normalizing heat treatment. The alloy steel weld metals' mechanical properties, tensile and Charpy V toughness testing and microhardness measurements were evaluated. His results show the effect of normalizing heat treatment on welds metal properties: the original as welded metal fine grained microstructure is changed to a coarse equiaxed ferrite with ferrite-carbide aggregates and the yield tensile strength properties are considerably reduced.

Kalandyk and Zapała [7] carried out a study to investigate the effect of prolonged time of holding at the temperature of $620^{\circ} \mathrm{C}$ on the processes of secondary phase precipitation and mechanical properties of low-alloy cast steel with an addition of vanadium subjected to two variants of heat treatment. This study shows that the application of complex heat treatment holding at the temperature of $620^{\circ} \mathrm{C}$ for 10 hours cannot guarantee the required improvement of mechanical properties compared with the common type of heat treatment during which the time of holding at a given temperature is adjusted to the casting wall thickness.

Pang [8] studied the form of the hardness gradient in the heat affected zones (HAZs) produced by submerged arc welding of two low-carbon Q \& T steels. Their results were shown unequivocally that the gradient differs from that found in steels of lower carbon equivalent in that the peak HAZ hardness was displaced from the grain coarsened heat affected zone (GCHAZ) into the grain refined heat affected zone (GRHAZ).

Ebert and Winsor [9] showed background information on the subject of tensile strength and resistance to wet $\mathrm{H}_{2} \mathrm{~S}$ cracking of carbon steel submerged arc welds obtained from reviewing industrial alloy steel weld metals' mechanical properties, tensile and Charpy $\mathrm{V}$ toughness testing and microhardness measurements.

Hamedi M. [10] studied the effect of process parameters including heating and post-weld heating power, and their corresponding duration along with interference, on the tensile strength of the welded joint was experimentally investigated.

It was found that with increasing the current, mechanical strength of the joint will increase to a specific limit and then decrease with a mild gradient. The mechanical strength of the joint increases with the time of heating; this behavior will improve to a specific limit and then subside to a particular value. Increasing the current augments the mechanical strength of the joint to a specific limit preceding a mild decrease afterward. The effect of post-welding heat on the tensile strength is evaluated and shows that this parameter has a remarkable effect exceeding 50\% improvement in tensile strength. Increase in the interface of abutting surface causes the mechanical strength of the joint to increase. The study shows the direct effect of time and current in heating stage on mechanical strength with a steeper gradient. Therefore it can be stated that these parameters have a strong effect on the UW process.

Rasool and Zaidi [11] studied the influence of post weld heat treatment on the fracture toughness of low-alloy steel weldments using standard COTD test and reported correlated results.

This study showed a higher fracture toughness due to material homogeneity, as welded weld metal has lower COTD values. These properties are in high priority for structural steel if these can be blended with high tensile strength. When comparing the base metal and HAZ, the base metal showed higher fracture toughness compared with welded HAZ.

In the present work four different steel alloys with varying weight percentages of $\mathrm{Ni}$ and $\mathrm{Cr}$ were tested to in- 
vestigate the effects of alloying elements. The effects were characterized according to the presence of alloying elements either alone or in conjunction with each other in the low carbon steel samples. The steel samples were characterized using mechanical testing methods. Tensile strength and elongation data were collected to study the effects of heat treatment and alloying elements. Metallographic and microstructure analysis was also carried out to draw a correlation between alloying elements and microstructural features.

\section{Experimental Work}

\subsection{Samples Preparation}

Four different steels containing about $0.11 \%$ carbon were used in this experimental study. Table 1 shows the composition of the steels alloy. Steel 1 is the base steel with which the structure and properties of other steels 2, 3 and 4 are compared. 2 samples have diameter $10 \mathrm{~mm}$ and 2 samples have diameter $14 \mathrm{~mm}$ with deferent chemical composition. Thus each sample has specific mechanical and microstructure properties of each sample.

The steels were made previously in an air induction furnace. About $14 \mathrm{~mm}$ diameter specimens were rolled down from $16 \mathrm{~mm}$ diameter bars of each of the steels in order to study the austenite grain coarsening behavior.

Table 1. (a) Chemical analysis for specimen 1; (b) Show chemical analysis for specimen 2; (c) Show chemical analysis for specimen 3; (d) Show chemical analysis for specimen 4.

(a)

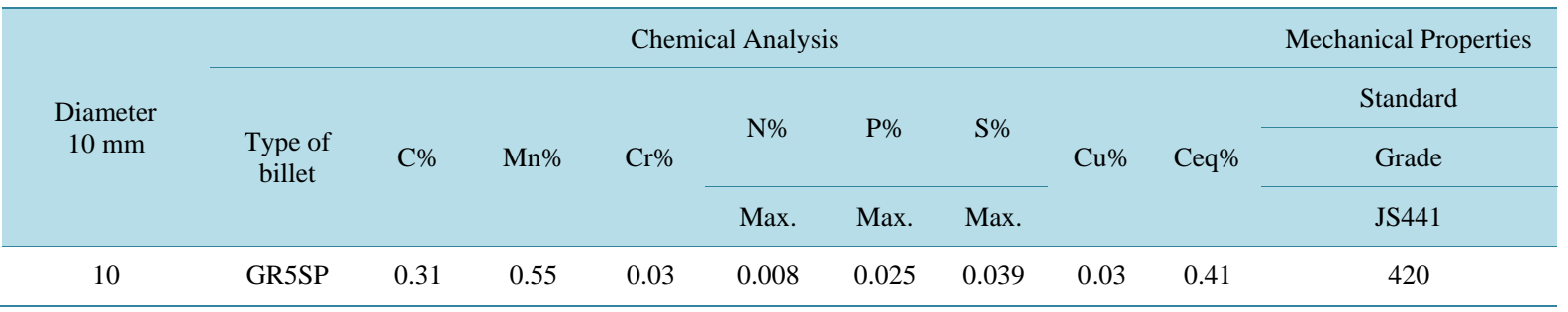

(b)

\begin{tabular}{|c|c|c|c|c|c|c|c|c|c|c|}
\hline \multirow{4}{*}{$\begin{array}{c}\text { Diameter } \\
10 \mathrm{~mm}\end{array}$} & \multicolumn{9}{|c|}{ Chemical Analysis } & \multirow{3}{*}{$\begin{array}{c}\text { Mechanical Properties } \\
\text { Standard } \\
\text { Grade }\end{array}$} \\
\hline & \multirow{3}{*}{$\begin{array}{c}\text { Type of } \\
\text { billet }\end{array}$} & \multirow{3}{*}{$\mathrm{C} \%$} & \multirow{3}{*}{$\mathrm{Mn} \%$} & \multirow{3}{*}{$\mathrm{Cr} \%$} & \multirow{2}{*}{$\mathrm{N} \%$} & \multirow{2}{*}{$\mathrm{P} \%$} & \multirow{2}{*}{$\mathrm{S} \%$} & \multirow{3}{*}{$\mathrm{Cu} \%$} & \multirow{3}{*}{ Сeq\% } & \\
\hline & & & & & & & & & & \\
\hline & & & & & Max. & Max. & Max. & & & BS4449 \\
\hline 10 & GR(500) & 0.24 & 0.66 & 0.13 & 0.006 & 0.020 & 0.050 & 0.41 & 0.41 & 500 \\
\hline
\end{tabular}

(c)

\begin{tabular}{|c|c|c|c|c|c|c|c|c|c|c|}
\hline \multirow{3}{*}{$\begin{array}{c}\text { Diameter } \\
\mathrm{mm}\end{array}$} & \multicolumn{9}{|c|}{ Chemical Analysis } & \multirow{2}{*}{$\begin{array}{c}\text { Mechanical Properties } \\
\text { Standard } \\
\text { Grade }\end{array}$} \\
\hline & $\begin{array}{c}\text { Type of } \\
\text { billet }\end{array}$ & $\mathrm{C} \%$ & $\mathrm{Mn} \%$ & $\mathrm{Cr} \%$ & N\% & $\mathrm{P} \%$ & S\% & $\mathrm{Cu} \%$ & Ceq\% & \\
\hline & & & & & Max. & Max. & Max. & & & BS4449 \\
\hline 14 & GR(500) & 0.23 & 0.53 & 0.13 & 0.009 & 0.020 & 0.025 & 0.35 & 0.38 & 500 \\
\hline
\end{tabular}

(d)

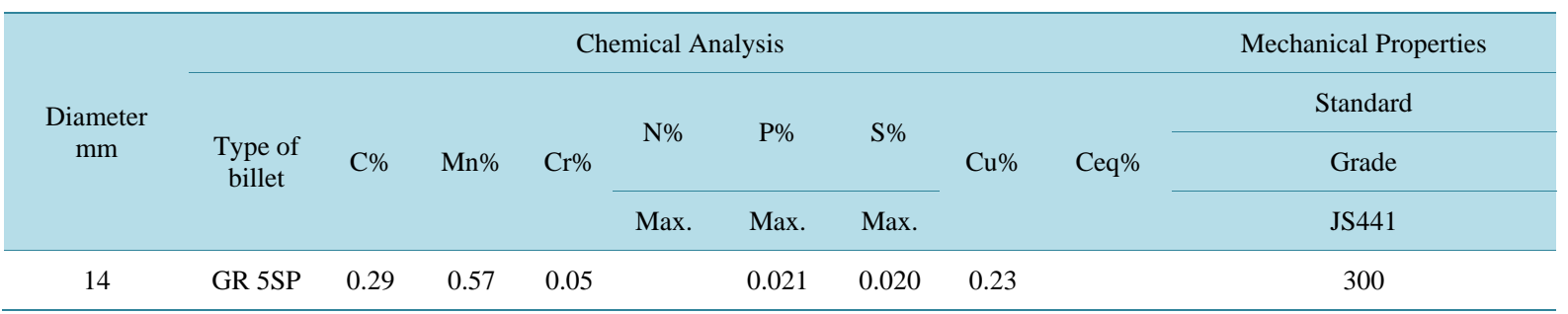




\subsection{Pre-Test Operation}

As mentioned previously four rods of steel with deferent chemical compositions, the work was divided into four groups with one rod in each, this rod was cut in to four pieces.

For tensile test the work piece was of length $30 \mathrm{~cm}$, and for impact test the work piece has a dimension (5.5 $\mathrm{cm} \times 1 \mathrm{~cm} \times 1 \mathrm{~cm}$ ) these samples were made by CNC milling machine and a Charpy notch was made in the center of length and angel $45^{\circ}$ and depth $2 \mathrm{~mm}$ by using a lath machine as shown in the Figure 1.

The microstructure work piece was cut along of its length $1.5 \mathrm{~cm}$ and a machine was used to make moulds of plastic as shown as in Figure 2, which helps to catch the specimen easily on the testing machine called Moulding.

A pail of water was used to immersion the sample rod after heat treatment, this operation knows as quenching.

\subsection{Carburization and Measurement of Austenite Grain Size}

Since size of the austenite grains directly affect the subsequent structure and hence the properties of steels, a study was made to determine prior austenite grain size at temperatures higher than upper critical temperature Carburization technique was used to reveal prior austenite grain size. There are also other methods in determining prior austenite grain size like isothermal transformation technique, oxidation technique. But previous work showed that the isothermal technique did not work well in revealing prior austenite grain boundary of low alloy steels [12]. Therefore, carburization technique was adopted to reveal prior austenite grain boundaries of steels in this work.

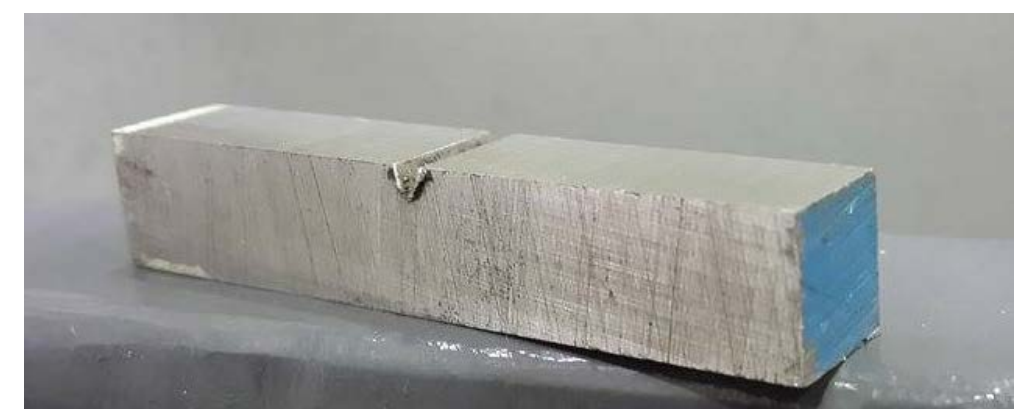

Figure 1. Impact piece.

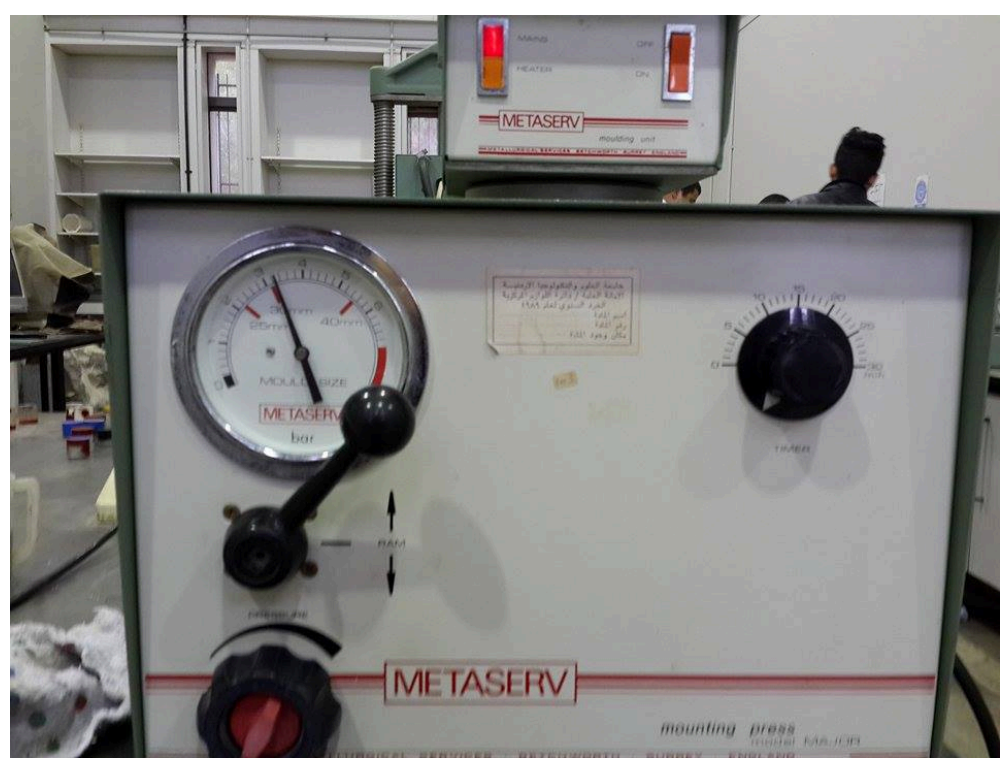

Figure 2. Moulding unit. 
The technique is based on the formation of a continuous cementite network at the austenite grain boundaries. Carbon will diffuse in steel from the carburizing atmosphere forming hypereutectoid steel at the surface of the specimen and during slow cooling in the furnace continuous cementite network is formed at the austenite grain boundaries at the selected austenitizing temperatures.

Subsequent etching of the furnace cooled samples revealed the cementite network formed which marked the prior austenite grain size at the selected carburizing temperatures [13].

Solid carburizing or pack carburizing technique was applied in this experimental study. The steel specimens were heated to different austenitizing temperatures, i.e. $900^{\circ} \mathrm{C}-1050^{\circ} \mathrm{C}$ with an interval of $50^{\circ} \mathrm{C}$. Before heating these specimens, they were packed in a pot with carburizing mixture. Then they were placed in Blue-M furnace.

After reaching the desired temperature, they were held at that temperature for $2 \mathrm{~h}$ to reach near the equilbrium conditions and then cooled in the furnace to the room temperature. Slow cooling ensured a continuous cementite network through the austenite grain boundaries.

The assessment of prior austenite grain size was made from direct measurement of the austenite grains in the specimens under optical microscope. The grain size was measured using the mean linear intercept method, counting grain boundary intersections with the circumference of the circle in the eyepiece of a microscope. The effective circumference of the circle was determined precisely by measuring its diameters with reference to a stage micrometer at the magnification used. A total of at least 300 - 600 intersections were counted for each specimen. Then the size of austenite grain was measured using the mean linear method.

\section{Experimental Results}

Tensile testing is a fundamental materials test in which a sample is subjected to a controlled tension until failure. The results from the test are commonly used to select a material for an application, quality control, and to predict how a material will react under other types of forces. Properties that are directly measured through a tensile test are ultimate tensile strength, maximum elongation and reduction in area. From these measurements the following properties can be determined: modulus, Poisson's, yield strength, and strain-hardening characteristics. Uniaxial tensile testing is the most commonly used for obtaining the mechanical properties.

A tensile specimen as shown as in Figure 3 with a standardized sample cross-section. It has two shoulders and a gauge (section) in between. The shoulders are large so they can be readily gripped, whereas the gauge section has a smaller cross-section so that the deformation and failure can occur in it. Figure 4 illustrates the most common types of shoulders. Keys A through C are for round specimens, whereas keys D and E are for flat specimens.

A standard specimen is prepared in a round section along the gauge length, depending on the standard used. Both ends of the specimens should have sufficient length and a surface condition such that they are firmly gripped during testing. The initial gauge length Lo is standardized (in several countries) and varies with the diameter (Do) or the cross-sectional area (Ao) of the specimen as shown as in Figure 5.

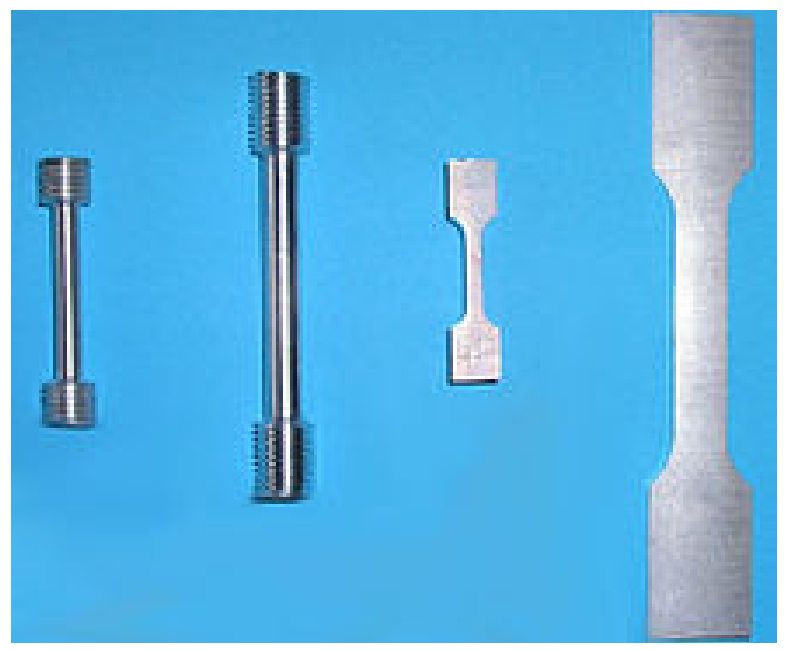

Figure 3. Moulding unit. 


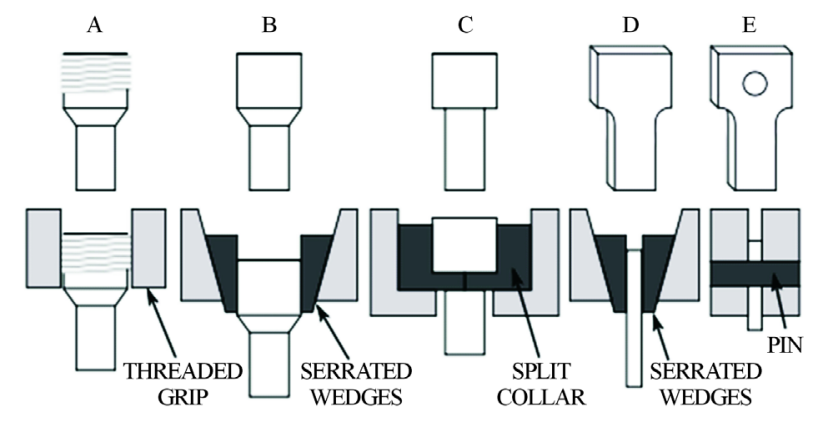

Figure 4. Various shoulder styles.

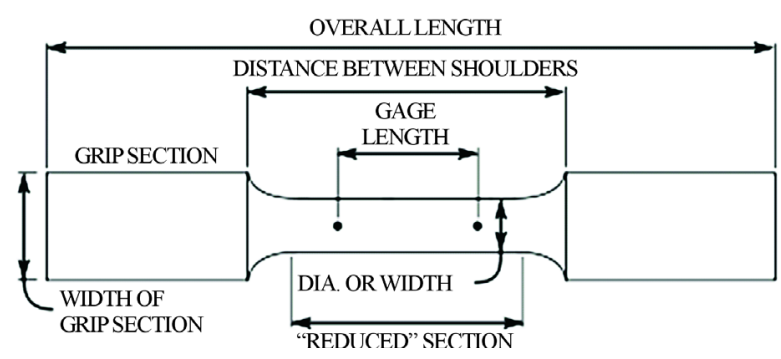

Figure 5. Test specimen nomenclature.

\subsection{Testing Equipments}

The most common testing machine used in tensile testing is the universal testing machine as shown as in Figure 6.

Alignment of the test specimen in the testing machine is critical, because if the specimen is misaligned, either at an angle or offset to one side, the machine will exert a bending force on the specimen. This is especially bad for brittle materials, because it will dramatically skew the results. This situation can be minimized by using spherical seats or U-joints between the grips and the test machine. If the initial portion of the stress-strain curve is curved and not linear, it indicates the specimen is misaligned in the testing machine.

The strain measurements are most commonly measured with an extensometer, but strain gauges are also frequently used on small test specimen or when Poisson's ratio is being measured. Newer test machines have digital time, force, and elongation measurement systems consisting of electronic sensors connected to a data collection device (often a computer) and software to manipulate and output the data. However, analog machines continue to meet and exceed ASTM, NIST, and ASM metal tensile testing accuracy requirements, continuing to be used today.

\subsubsection{Stress-Strain Curve}

The relationship between the stress and strain that a particular material displays is known as that particular material's stress-strain curve. It is unique for each material and is found by recording the amount of deformation (strain) at distinct intervals of tensile or compressive loading.

Stress-strain curves of various materials vary widely, and different tensile tests conducted on the same material yield different results, depending upon the temperature of the specimen and the speed of the loading. It is possible, however, to distinguish some common characteristics among the stress-strain curves of various groups of materials and, on this basis, to divide materials into two broad categories; namely, the ductile materials and the brittle materials.

Figure 7 shows a typical stress-strain curve showing yield behavior for nonferrous alloys. Stress $(\sigma)$ is shown as a function of strain $(\epsilon)$. Point 1: Elastic (proportionality) limits and point 2: Offset yield strength $(0.2 \%$ proof strength.

\subsubsection{Impact Test}

Impact testing is testing an object's ability to resist high-rate loading. An impact test is a test for determining the 


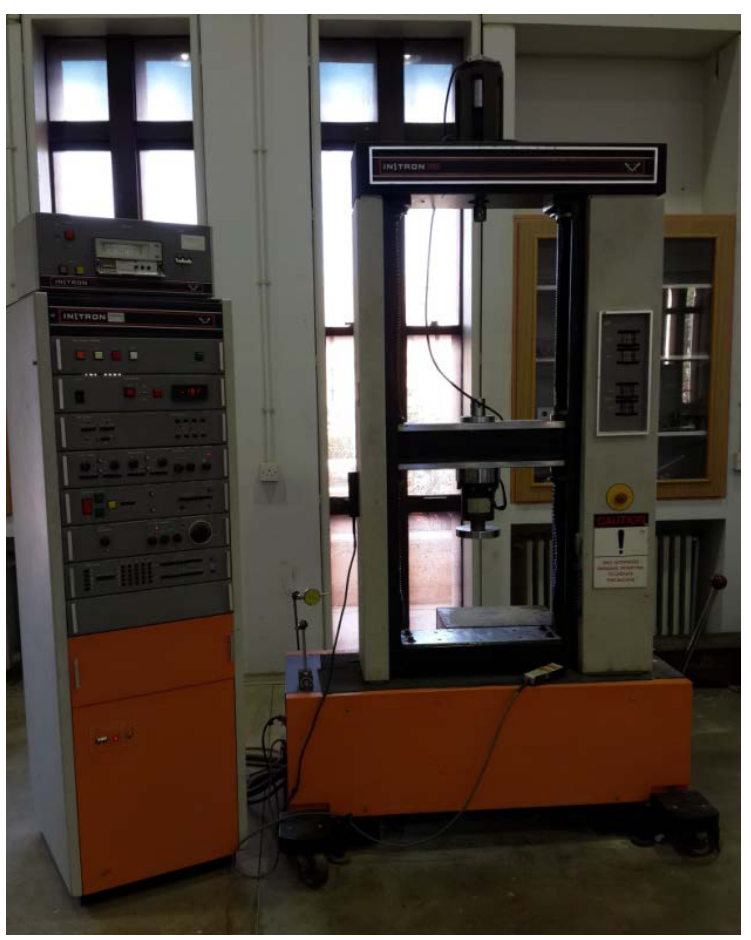

(a)

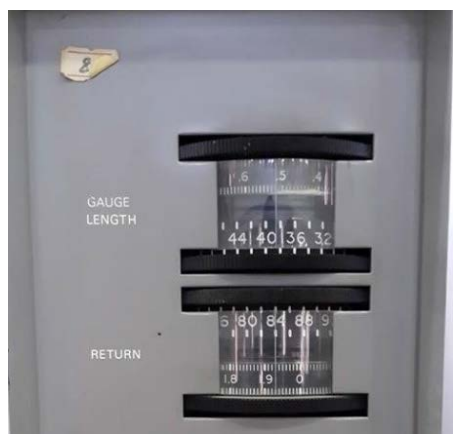

(b)

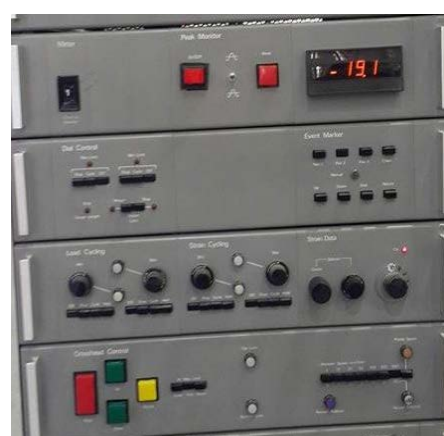

(c)

Figure 6. (a) A universal testing machine (Hegewald \& Peschke); (b) Gauge length; (c) Panel load control.

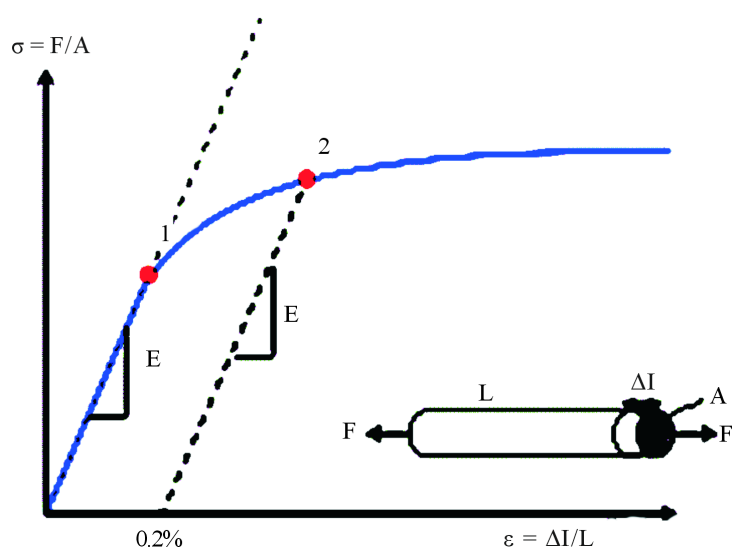

Figure 7. Stress-strain curve showing typical yield behavior for nonferrous alloys. 
energy absorbed in fracturing a test piece at high speed. Impact resistance is one of the most important properties for a part designer to consider, and without question, the most difficult to quantify. The impact resistance of a part is, in many applications, a critical measure of service life. More importantly these days, it involves the perplexing problem of product safety and liability.

The Charpy impact testis a standardized high strain-rate test which determines the amount of energy absorbed by a material during fracture. This absorbed energy is a measure of a given material's notch toughness and acts as a tool to study temperature-dependent ductile-brittle transition. It is widely applied in industry, since it is easy to prepare and conduct with a results can be obtained quickly and cheaply. A disadvantage is that some results are only comparative, the impact test machine as shown as in Figure 8.

\subsubsection{Microstructure}

Microstructure is defined as the structure of a prepared surface or thin foil of material as revealed by a microscope as shown as in Figure 9 above $25 \times$ magnification. The microstructure of a material can strongly influence physical properties such as strength, toughness, ductility, hardness, corrosion resistance, high/low temperature behavior, wear resistance, and so on, which in turn govern the application of these materials in industrial practice. Microstructure at scales smaller than can be viewed with optical microscopes is often called ultra structure or nanostructure.

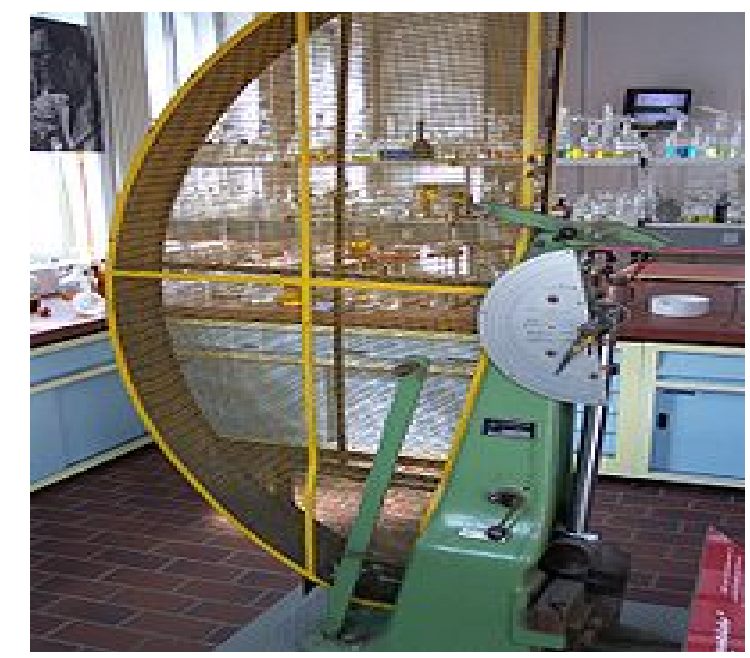

Figure 8. A vintage impact test machine.

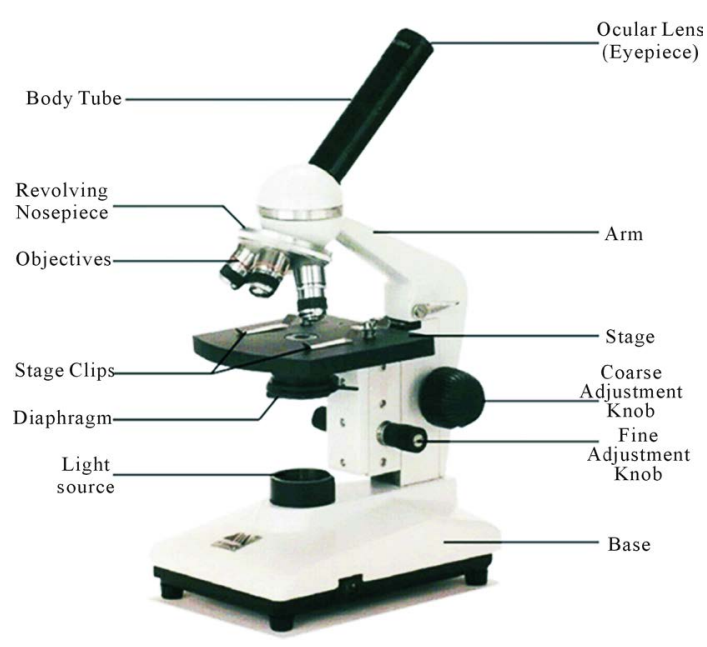

(a)

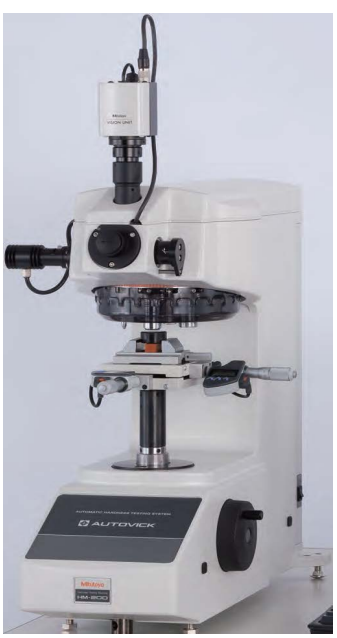

(b)

Figure 9. (a) Microscope \& parts; (b) Micro Vickers hardness testing machines. 
After preparing the specimens (cutting and make a moulds) we are grinding it by using paper grinding which have deferent degrees (60 - 120 - 180 - 220 - 320 - 420) where the increase in the degrees indicate the increase smoothness, after that we are polishing it using the paper polisher have great degree (1200) with diamond particles, then putting in nitric acid to indicate the grain boundaries. After every step were the specimens washed with alcohol. After that we use a microscope to see the grains and grain boundaries.

\subsubsection{Microvickers Hardness}

The Vickers hardness test method, also referred to as a micro hardness test method, is mostly used for small parts, thin sections, or case depth work. The Vickers method is based on an optical measurement system. The Micro hardness test procedure specifies a range of light loads using a diamond indenter to make an indentation which is measured and converted to a hardness value. It is very useful for testing on a wide type of materials as long as test samples are carefully prepared. A square base pyramid shaped diamond is used for testing in the Vickers scale. Typically loads are very light, ranging from a few grams to one or several kilograms, although "Macro” Vickers loads can range up to $30 \mathrm{~kg}$ or more. The Micro hardness methods are used to test on metals, ceramics, and composites - almost any type of material.

Since the test indentation is very small in a Vickers test, it is useful for a variety of applications: testing very thin materials like foils or measuring the surface of a part, small parts or small areas, measuring individual microstructures, or measuring the depth of case hardening by sectioning a part and making a series of indentations to describe a profile of the change in hardness. The Vickers method is more commonly used.

Sample preparation is usually necessary with a micro hardness test in order to provide a small enough specimen that can fit into the tester. Additionally, the sample preparation will need to make the specimen's surface smooth to permit a regular indentation shape and good measurement, and to ensure the sample can be held perpendicular to the indenter. Usually the prepared samples are mounted in a plastic medium to facilitate the preparation and testing. The indentations should be as large as possible to maximize the measurement resolution (error is magnified as indentation sizes decrease). The test procedure is subject to problems of operator influence on the test results, in Figure 9 show Micro Vickers Hardness Testing Machines.

\section{Result and Discussion}

\subsection{The Result and Discussion of Tensile Test}

\section{Result and Discussion Sample 1}

In the sample 1 we were test mechanical properties before Heat treatment and after heat treatment at $\left(800^{\circ} \mathrm{C}\right.$, $950^{\circ} \mathrm{C}, 1100^{\circ} \mathrm{C}$ ), the result after test:

It was shown that the steel was ductile material before heat treatment as shows in Figure 10 the carve started as a liner line after that show nicking zone it was guided in upper yield point at $\left(405.97 \mathrm{~N} / \mathrm{mm}^{2}\right)$ and lower yield point at $\left(405.35 \mathrm{~N} / \mathrm{mm}^{2}\right)$ and after that fracture point at which the value of elongation equal $18.46 \%$.

Figure 11 illustrate the stress strain curve after heat treatment, it is clear that the material became brittle as a raped cooling after quenching operation, and the value of elongation at $800^{\circ} \mathrm{C}$ equal $0.94 \%$ and at $950^{\circ} \mathrm{C}$ equal $0.83 \%$ and at $1100^{\circ} \mathrm{C}$ equal $0.96 \%$.

In the sample 2 were tested to obtain the mechanical properties before and after heat treatment at $\left(800^{\circ} \mathrm{C}\right.$, $950^{\circ} \mathrm{C}, 1100^{\circ} \mathrm{C}$.

Figure 12 shows the stress-strain diagram of sample 2 before heat treatment. It can be seen that, the steel was ductile material, the carve started as liner line after that it shows nicking zone guided in upper yield point at $\left(515.99 \mathrm{~N} / \mathrm{mm}^{2}\right)$ and lower yield point at $\left(507.47 \mathrm{~N} / \mathrm{mm}^{2}\right)$. The value of elongation is equal $12.03 \%$ after the fracture point.

The stress strain curve for sample 2 after heat treatment is shown in Figure 13. It is obvious that the material became brittle due to raped cooling or quenching operation. The elongation values decreases as the temperature increases. The value of elongation at $800^{\circ} \mathrm{C}$ equal $1.25 \%$ and at $950^{\circ} \mathrm{C}$ equal $0.94 \%$ and at $1100^{\circ} \mathrm{C}$ equal $0.96 \%$.

The stress strain diagrams of sample 3 before and after heat treatment are shown in Figure 14 and Figure 15 respectively. It can be seen that the curve started in liner line and then tend to nicking guided with an upper yield point at $\left(566 \mathrm{~N} / \mathrm{mm}^{2}\right)$ and lower yield point at $\left(564.65 / \mathrm{mm}^{2}\right)$ finally the fracture point elongation equal is equal to $11.68 \%$.

After heat treatment the material became brittle due to raped cooling and the value of elongation at $800^{\circ} \mathrm{C}$ is 


\section{Result Data}

Tensile Strength $(\mathrm{Rm}) \mathrm{N} / \mathrm{mm}^{2}$. $\quad 676.04$

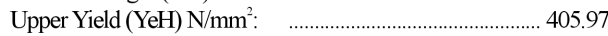

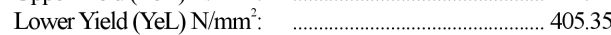

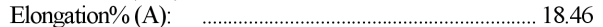

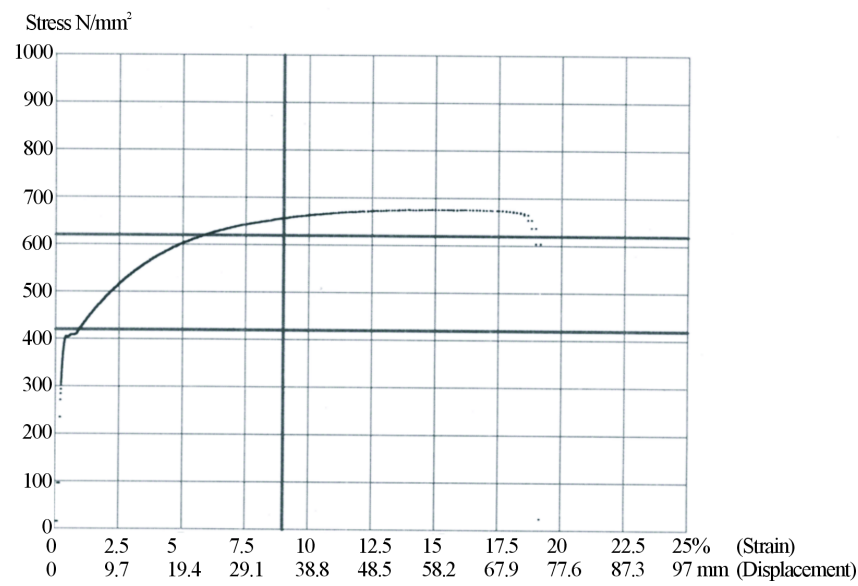

Figure 10. Sample 1 before heat treatment.

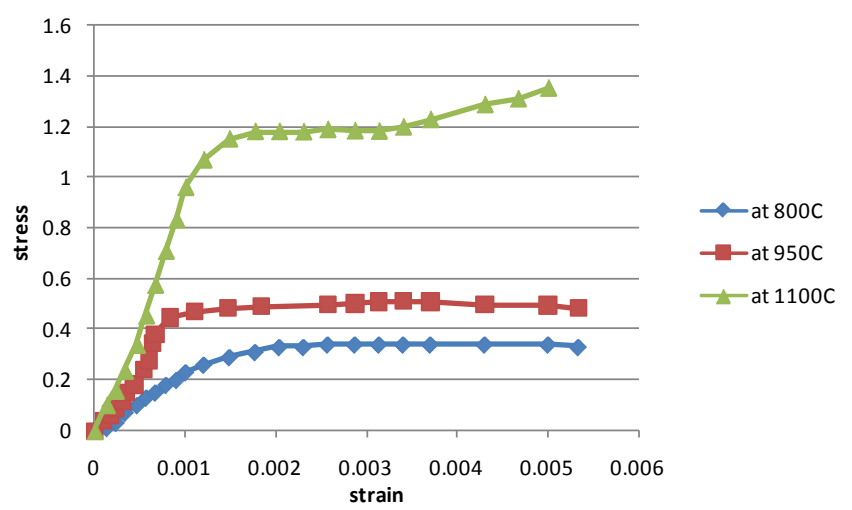

Figure 11. The result after heat treatment.

\section{Result Data}

\begin{tabular}{|c|c|}
\hline Tensile Strength $(\mathrm{Rm}) \mathrm{N} / \mathrm{mm}^{2}$ : & $\ldots 616.47$ \\
\hline Upper Yield (YeH) N/mm²: & 515.99 \\
\hline $\begin{array}{l}\text { Lower Yield (YeL) N/mm²: } \\
\text { Elongation } \%(\mathrm{~A})\end{array}$ & 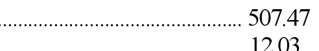 \\
\hline
\end{tabular}

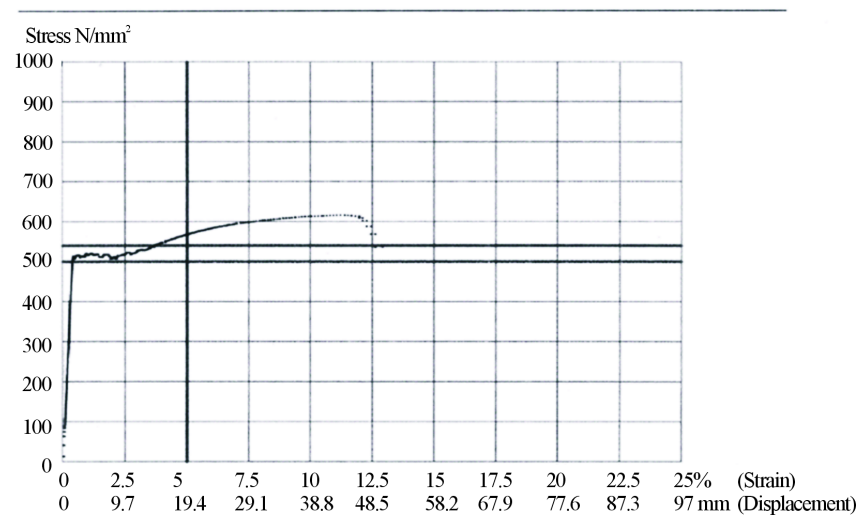

Figure 12. Sample 2 before heat treatment. 


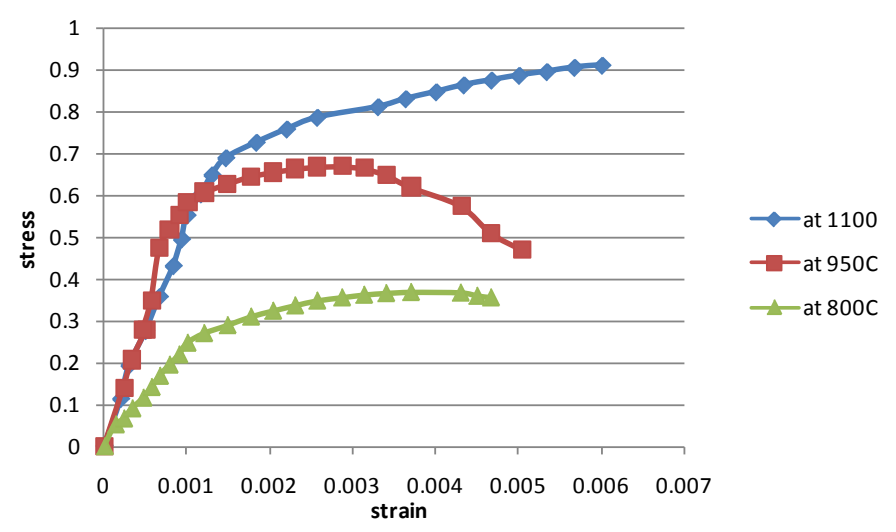

Figure 13. The result after heat treatment.

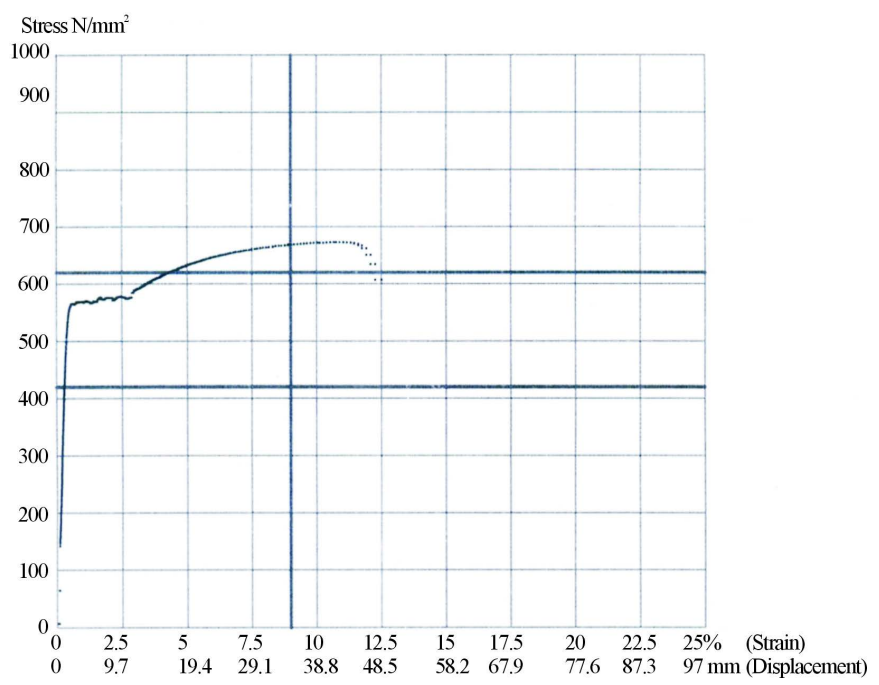

Figure 14. Sample 3 befor heat tretment.

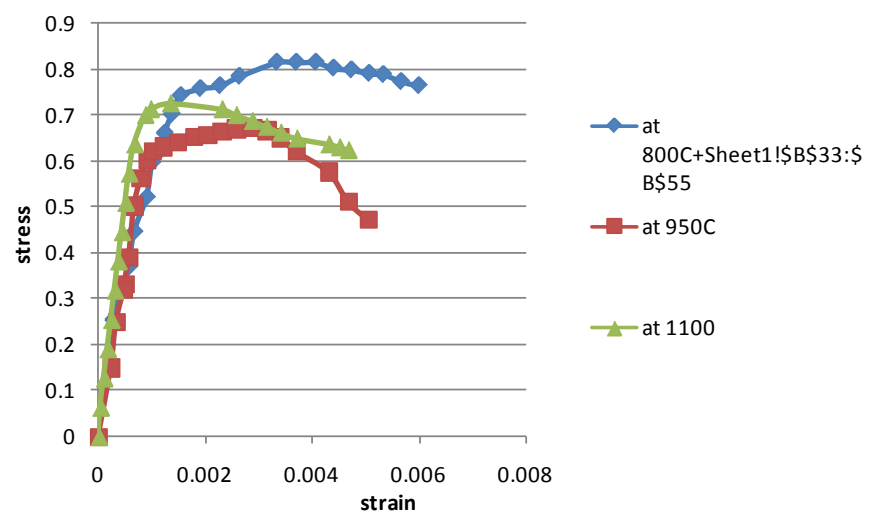

Figure 15. The result after heat treatment.

equal $1.02 \%$ and at $950^{\circ} \mathrm{C}$ is equal $1.15 \%$ and at $1100^{\circ} \mathrm{C}$ is equal $1.08 \%$ (see Figure 15 ).

\subsection{The Result and Discussion of Impact Test}

Four samples of alloy steel were tested on the impact testing machine. The dimension of impact specimens: are: Charpy: veffective $=8 \times 40 \times 10=3200 \mathrm{~mm}^{3}=3.2 \times 10^{-6} \mathrm{~m}^{3}$ (Figure 16). 


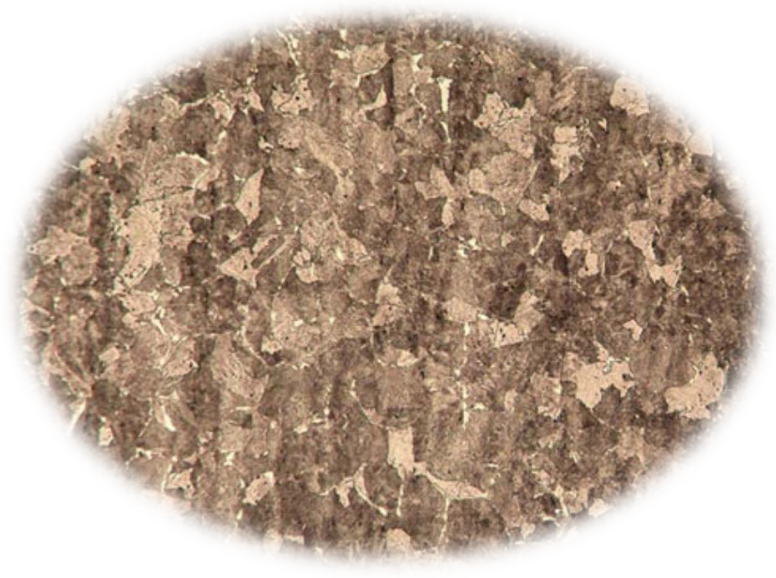

(a)

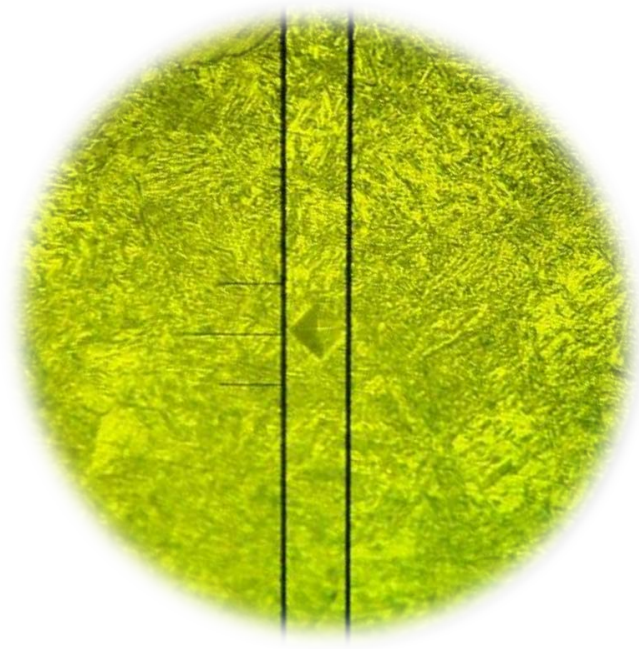

(c)

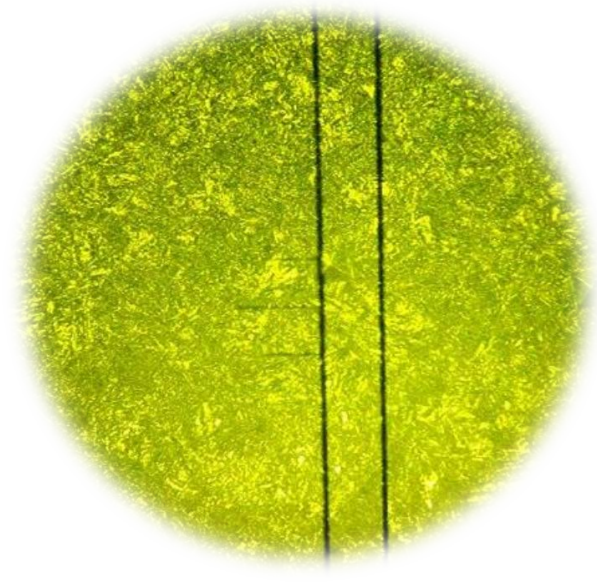

(b)

Figure 16. (a) Sample 1 microstructure before heat treatment; (b) Sample 1 microstructure after heat treatment at $800^{\circ} \mathrm{C}$; (c) Sample 1 microstructure after heat treatment at $950^{\circ} \mathrm{C}$; (d) Sample 1 microstructure after heat treatment at $1100^{\circ} \mathrm{C}$.

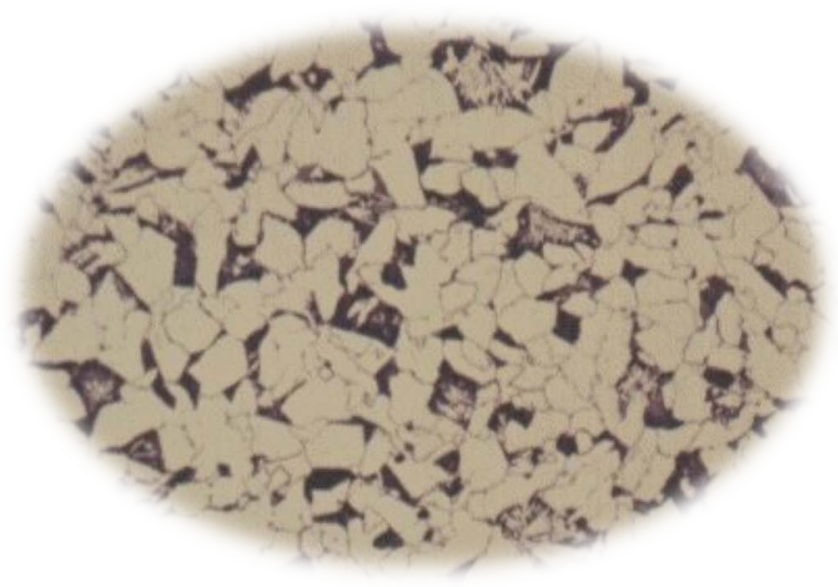

(a)

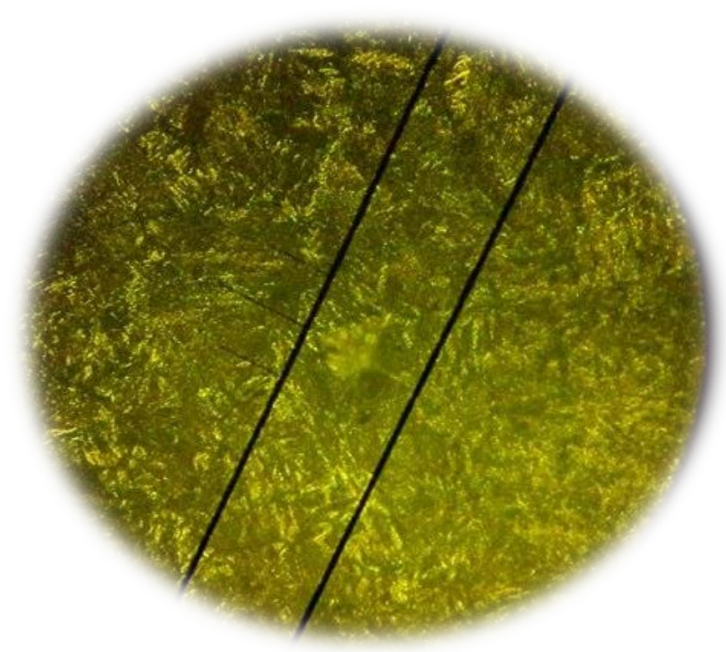

(d)

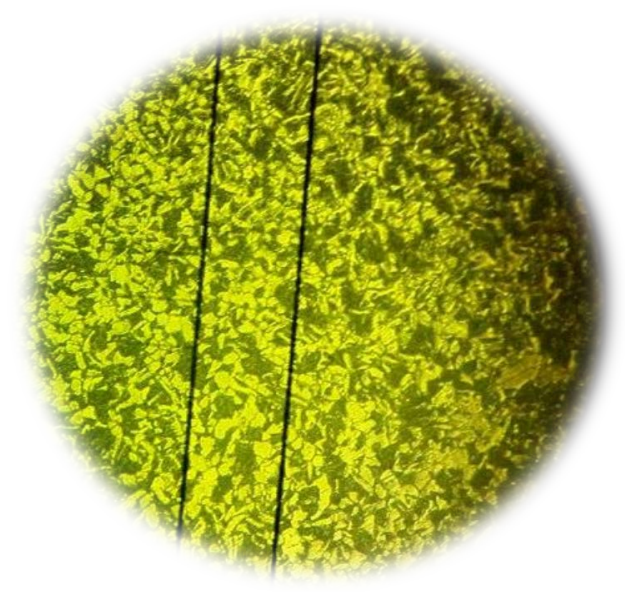

(b) 


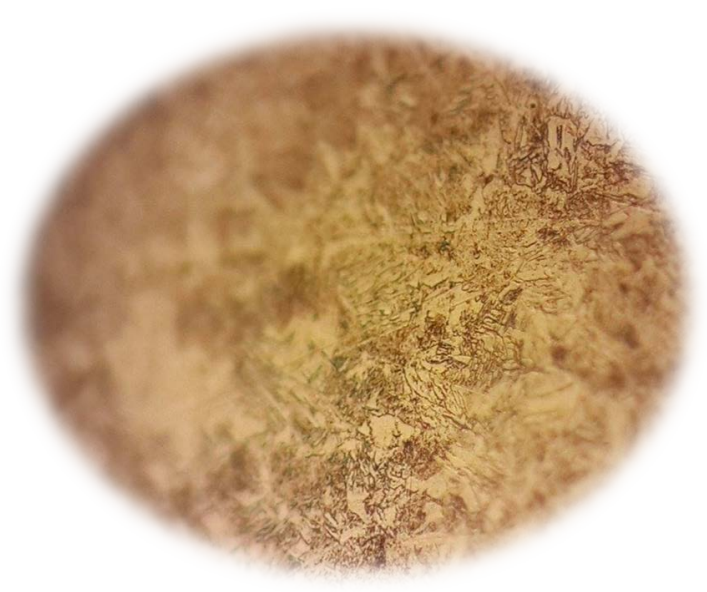

(c)

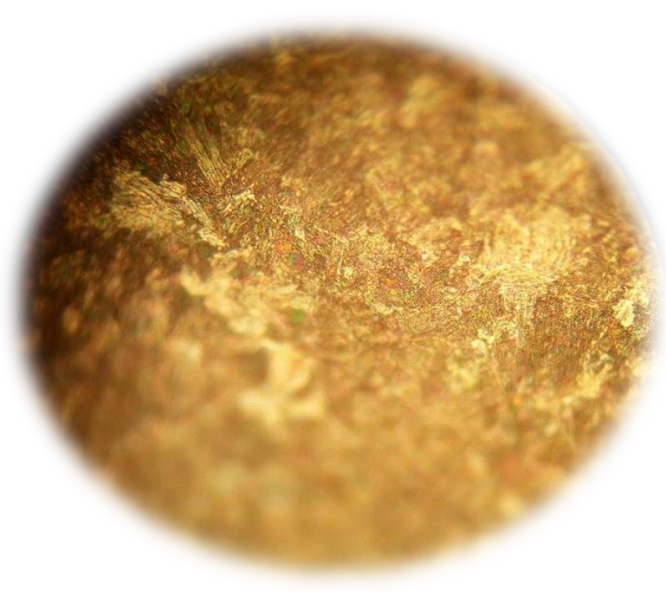

(d)

Figure 17. (a) Sample 3 microstructure before heat treatment; (b) Sample 3 microstructure after heat treatment at $800^{\circ} \mathrm{C}$; (c) Sample 3 microstructure after heat treatment at $950^{\circ} \mathrm{C}$; (d) Sample 3 microstructure after heat treatment at $1100^{\circ} \mathrm{C}$.

Figure 17 illustrates the effect of heat treatment at different temperatures on the micro structure of sample 2.

\section{Conclusion}

The effect of heat treatment at three different temperatures of $800^{\circ} \mathrm{C}, 950^{\circ} \mathrm{C}$ and $1100^{\circ} \mathrm{C}$ on the microstructure and mechanical properties of low-alloy steel containing manganese, chrome and lead were experimentally investigated. In order to determine an impact of heat treatment operations, testing of mechanical properties and microstructural examinations of the steel with $0.23 \%, 0.24 \%, 0.29 \%$ and $0.31 \% \mathrm{C}$ were carried out. This work shows that the mechanical strengths of the alloy steel are improved with increasing the heat treatment temperature. In addition, the microstructure trends toward recrystallized ferrite grains as the heat treatment temperature increases.

\section{References}

[1] Aver, S.H. (1974) Introduction to Physical Metallurgy. 2nd Edition, McGraw-Hill Book Company, New York.

[2] American Society for Metals (1964) Metal Handbook Vol. 2. 8th Edition, American Society for Metals, Materials Park, Ohio.

[3] Roberti, R., Cornacchia, G. and Faccoli, M. (2012) Effect of Increasing Post Weld Heat Treatment Temperature on the Fracture Toughness of an ASME SA-542M Steel. Forni di Sopra (UD), Italia.

[4] Razzak, M.A. (2011) Heat Treatment and Effects of Cr and Ni in Low Alloy Steel. Bulletin of Materials Science, 34, 1439-1445. http://dx.doi.org/10.1007/s12034-011-0340-9

[5] Mohyla, P., Tomčík, P., Beneš, L. and Hlavatý, I. (2011) Influence of Post Weld Heat Treatment on Secondary Hardening of CrMoV Welded Joints. Metal Science and Heat Treatment, 53, 374-378. http://dx.doi.org/10.1007/s11041-011-9401-3

[6] da Trindade Filho, V.B., Guimarães, A.S., Payão Filho, J. da C. and Paranhos, R.P. da R. (2004) Normalizing Heat Treatment Effects on Low Alloy Steel Weld Metals. Journal of the Brazilian Society of Mechanical Sciences and Engineering, 26.

[7] Kalandyk, B. and Zapała, R. (2008) Effect of Heat Treatment Parameters on the Properties of Low-Alloy Cast Steel with Microadditions of Vanadium. Archives of Foundry Engineering, 8, 137-140.

[8] Pang, W., Ahmed, N. and Dunne, D. (2011) Hardness and Microstructural Gradients in the Heat Affected Zone of Welded Low-Carbon Quenched and Tempered Steels. Australasian Welding Journal, 56, 36-48.

[9] Ebert, H.W. and Winsor, F. (1984) Carbon Steel Submerged Arc Welds-Tensile Strength vs. Corrosion Resistance. Welding Research Supplement 1193-s.

[10] Hamedi, M. (2006) Optimizing Tensile Strength of Low-Alloy Steel Joints in Upset Welding. Journal of Achievements in Materials and Manufacturing Engineering, 17, 341-344.

[11] Mohideen, R. and Ahmed Zaidi, A.M. (2010) Influence of Post Weld Heat Treatment on the HAZ of Low Alloy Steel 
Weldments. International Journal of Integrated (Issue on Mechanical, Material and Manufacturing Engineering). http://eprints.uthm.edu.my/616/1/ijiev22010p2.pdf

[12] Zahirul, H.M. (1989) Effect of Alloying Elements in HSLA. MsC Engg. Thesis, Department of Metallurgical Engineering, BUET, Dhaka, 130-150.

[13] Clark, D.S. and Varney, W.R. (1962) Physical Metallurgy for Engineers. 2nd Edition, Litton Educational Publishing Inc., New York. 